\title{
Prevalence and Specificities of Red Cell Alloantibodies Among Blood Recipient's in the Islamic Republic of Pakistan
}

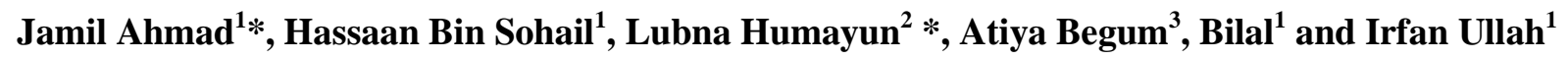 \\ ${ }^{1}$ Faculty of Allied Health Sciences University of Lahore, Lahore, Pakistan \\ ${ }^{2}$ University College of Medicine and Dentistry University of Lahore2 \\ ${ }^{3}$ Combined Military Hospital, Lahore Medical College2 \\ DOI: $10.29322 /$ IJSRP.10.10.2020.p10660 \\ http://dx.doi.org/10.29322/IJSRP.10.10.2020.p10660
}

\begin{abstract}
Objective: To determines the prevalence of red cell antibodies in incompatible cross match cases.

Study design: It was a cross-section descriptive study.

Method: ABO (forward and reverse) and Rh D grouping of donor and recipient's and serological cross matches are performed using Indirect Antiglobulin test. All incompatible cross match cases are further evaluated in immunohematology. The samples of recipient of incompatible cross match cases are subjected to DAT. Auto control red cell antibody screening and red cell antibody identification panels as required to save the discrepancies in individual cases.
\end{abstract}

Result: Total 37 incompatible cross matches cases performed during the study period. ABO discrepancy was the cause of incompatible cross match in 6 of these cases. The cause of incompatible was autoantibodies in 8, compatible after fresh sample were 9, auto immune hemolytic anemia were 8, and alloantibodies in 14 cases.

Conclusion: The IAT cross match is an essential part of compatibility testing before blood transfusion. Antibody screening is not routinely performed on donors or recipients. The cross match incompatible is usually the first indicator of presence of allo/auto antibodies in the recipient serum. The prevalence of $0.105 \%$ of incompatible cross match cases in this study stress the need of IAT cross match before red cell transfusion to avoid the life threating complications. It also signifies the importance of further evaluation of cross match incompatible cases to rule out the presence of significant antibodies.

\section{INTRODUCTION}

B lood transfusion is a life-saving treatment indicated in diverse clinical situation. Transfusion of safe and compatible blood is preliminary requirement for transfusion services. ${ }^{(1)}$

About 400 blood group antigens have been described. The clinical importance of blood group regarding transfusion line in developing antibodies against the lacking blood group antigen with a risk of transfusion reaction. The clinical importance of different blood group antigens differ but the $\mathrm{ABO}$ and $\mathrm{Rh}$ are of outmost importance. $\stackrel{(2)}{ }$
Accurate $\mathrm{ABO}$ grouping is one of the most important serological test required. Thus the polyclonal reagents have been largely replaced by monoclonal reagents. A and B cell are used for performing reverse grouping which is used to detect the reciprocal antibodies. To ensure that the reaction with $\mathrm{A}$ and $\mathrm{B}$ cell are not as a result of the presence of cold auto antibodies auto control may also be included. $\mathrm{Rh} \mathrm{D}$ grouping is also performing simultaneously with $\mathrm{ABO}$ for convenience and to minimize the clerical errors which occur due to repeated handling of patient's sample. ${ }^{(3,4)}$

Red cell antibodies can be naturally occurring. If present in the plasma of subject which had never been exposed to these antigen by injection, pregnancy or transfusion and immune mediated which are produced as a response to foreign antigen. ${ }^{(5)}$

Anti A and B are the most important one which fall in the this category are of IgM type reacting at room $(4-22 \mathrm{C})$ as well as $37 \mathrm{C}$ (body temperature ) immune antibodies are produced by the individual in response to the exposure of antigen by transfusion or trans - placental passage during pregnancy of red cell. These antibodies are of IgG type generally (with few exceptions where these remain as $\operatorname{IgM}$ ) .these antibodies react best at $37 \mathrm{C}$ and are also called warm antibodies. Only IgG antibodies have the capacity to cross the placenta from mother to fetus. The most important antibodies amongst this group are $\mathrm{Rh}$ antibodies. $\stackrel{(2,}{6})$

The red cell antibodies detection is crucial for safe blood transfusion.it is necessary in the investigation of suspected hemolytic transfusion reaction and immune hemolytic anemia. It is also important in detection and investigation of HDFN. Although these red cell antibodies are immune alloantibodies against red cell antigen simulated by transfusion, transplantation or pregnancy. However these can be naturally occurring produced without simulation. Naturally produced antibodies may develop through exposure to environmental antigen like pollen, fungus and bacteria having similar structure like red cell antigen. Furthermore these antibodies can be required passively through plasma products or salutation. Indirect antiglobuline test (IAT) is principle method for screening and identification of clinically significant red cell antibodies, which are of $\operatorname{IgG}$ type, reacting at 37 C. ${ }^{(7)}$ 
Presence of autoantibodies, defined as the antibodies directed against own red cell antigens may interfere in detection of clinically significant alloantibodies. ${ }^{(8)}$

The donor and the recipient sample should be typed for $\mathrm{ABO}$ and $\mathrm{Rh} \mathrm{D}$ and screened for red cell antibodies. The presence of auto and alloantibodies together can complicate the workup making the selection of appropriate cross match compatible red cell difficult, thus resulting in reduced post transfusion red cells survival, foreign antigen are potential immunogens, and may result in production of antibodies within days, weeks or months in the recipient after transfusion. Alloantibodies can result in reduced post transfusion survival of red cells, acute or delayed hemolytic transfusion reaction (HTR) and hemolytic disease of fetus and Newborn (HDFN). ${ }^{(9)}$

In case when antibodies screening is positive, test are performed to identify the antibodies by antibodies identification panel and RBC antigen phenotyping. Screening cells are prepared from two or three individual donors having blood group O and ideally expressing D, C, E, c, e, M, N, S, s, P, Le, K, k, Fy, and $\mathrm{jk}$, antigen. These cells must contain be antigens to detect the irregular clinically significant antibodies. It is also preferred to have at least one of the homozygous antigens expressing for the entire antigen for stronger reaction and ability of detection of weaker antibodies. $(\underline{10}, \underline{11})$

\section{Material and methods}

This is a cross sectional descriptive study that utilized data of all patients. Patients with missing data were excluded from the study. Clotted and EDTA blood sample of all incompatible cross match cases were collected. Serum was extracted and subjected to red cell antibody screening by using commercially available three cell panel and antibody identification by eleven cell panel. Other information sought for each patient included medical history, gender, age, and ethnic origin. The data were analyzed using the statistical package for social science (SPSS) software version 25 .

\section{RESULT:}

Total 37 incompatible cross matches' cases were performed during the study period. The data of investigation including antibody screening and identification was performed in immunohematology department.

Data was characterized in three variables according to blood group, Result and Allo immune specificity.

Out of 37 incompatible cross match cases 9 were compatible after repeating with fresh sample (9/37 24.32 \%). ABO discrepancies were detect in 6 of these cases $(16.21 \%)$ which Bombay $\mathrm{Rh} \mathrm{D}$ positive $2 / 6$, Bombay $\mathrm{RhD}$ negative $1 / 6$, $\mathrm{A} 2 \mathrm{~B}$ with anti-A1 1/6, week A antigen 1/6 week B antigen 1/6 (figure 1 ) . 8 of the cases were identified as auto immune hemolytic anemia( $21.62 \%) .14$ cases showed presence of alloantibodies ( $37.84 \%$ ) showed in figure 2 . Out of these 14 cases anti $M$ was most frequent $(4 / 1428.57 \%)$ followed by anti c ( $2 / 1414.28$ $\%)$, anti-D ( $2 / 1414.28 \%)$, anti-e (1/14 7.14 \%), anti-E (1/14 $7.14 \%)$, anti $\mathrm{Jk}^{\mathrm{a}}(1 / 147.14 \%)$, anti-S (1/14 7.14\%), anti E with $\mathrm{K}(1 / 147.14 \%)$, anti C with $\mathrm{K}$ and $\mathrm{E}(1 / 147.14 \%)$.

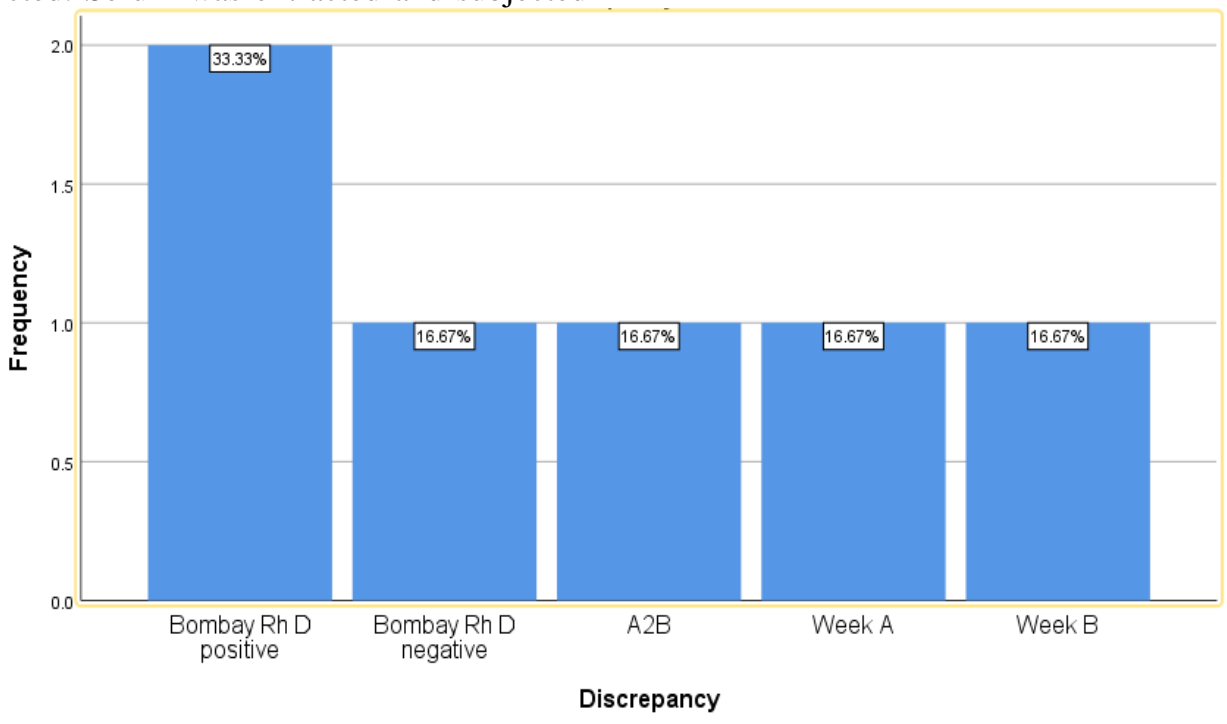

Figure - 2: Distribution of ABO discrepancy in incompatible cross matches. 


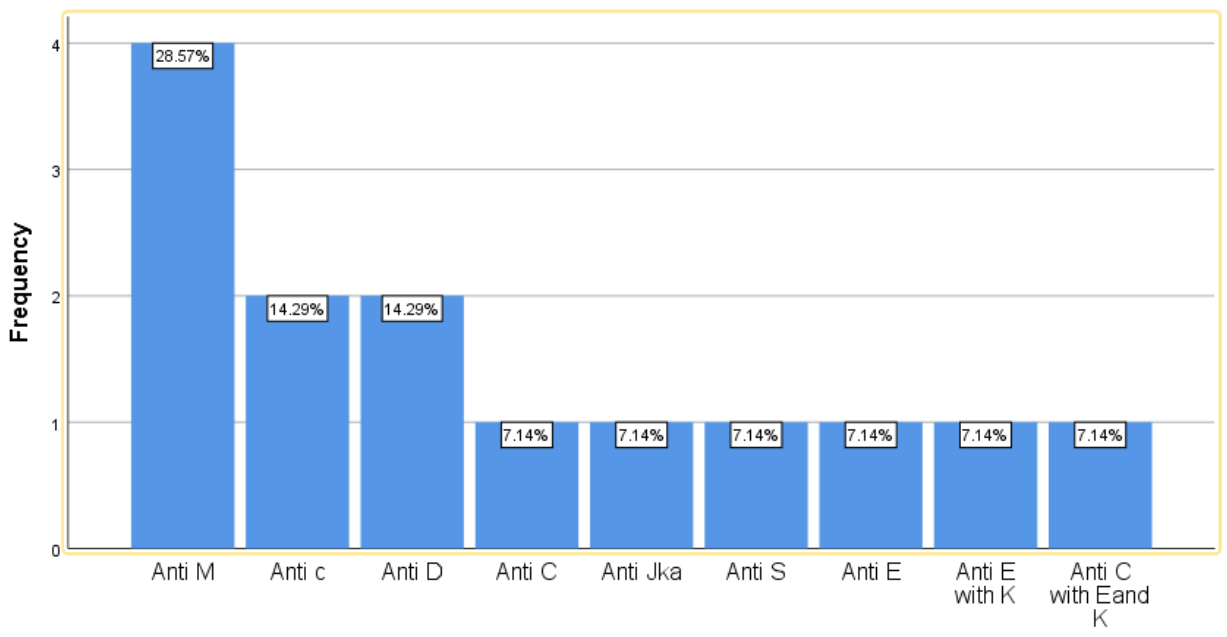

Alloantibodies

Figure - 2: Distribution of Red cell Allo Antibodies detected in Incompatible cross matches.

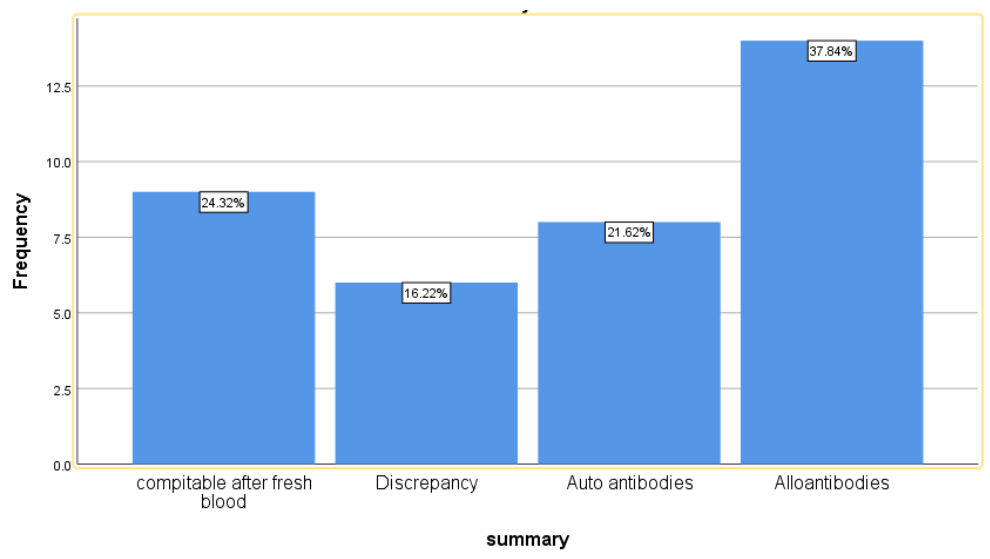

Figure - 4: summary of incomputable cross matches.

\section{DISCUSSION:}

Serological cross match is the most important part of compatibility testing in our part of world to ensure the safety of red cell transfusion. Red cell antibody screening is not performed on all donor or patient sample. However the incompatible cross match cases are subjected to further testing including red cell screening, identification ant globulin test and auto control.

The previous studies largely focused on multiply transfused patient population or antenatal women. A study at Ain Shams University Egypt, in multi transfused auto immune hemolytic anemia (AIHA) patient in 2014 revealed allo antibodies in about one fourth of these case in addition to autoantibodies. Anti E alloantibody was found to be commonest followed by anti $\mathrm{K}$, anti $\mathrm{Jk}^{\mathrm{a}}$, anti-D, anti-c, anti-M, anti-e, anti-Fy ${ }^{\mathrm{a}}$, anti-Fy and anti- $\mathrm{Jk}^{\mathrm{b}}$, in decreasing order. $\stackrel{(12)}{ }$

Another study at National University of Malaysia, Kualalampure, to determine the prevalence of red cell alloantibodies among blood recipient 2008 (n-5719) showed prevalence of allo immunization 65 individuals $(1.13 \%)$. The majority of these had a single alloantibody. The anti-E antibody identified as the most common allo antibody followed by the anti- $\mathrm{Le}^{\mathrm{a}}$ and anti-M antibodies. ${ }^{(13)}$
In a study performed at tertiary care hospital in Sokoto, Nigeria by Z, Isaacl, E Osarol, T,C, Adias et al on prevalence of clinically significant alloantibodies among transfusion Requiring patients in 2016 (n-229) that $14.85 \%$ of the patient had clinically significant alloantibodies in their plasma which is quite close to our studies. All the female individual were identified as anti-D and anti-c and half were identified anti-E in female followed by anti-jka, anti-Leb, anti-Fyb, anti-Pi and anti-Kp ${ }^{\mathrm{a}}$ each respectively. $\stackrel{(14)}{ }$

An Indian study determine the prevalence and specificity of red cell alloantibodies by Rahul Chaurasia et al in 2014 ( $n$ 11235), quied the incidence of red cell alloimmunazition in transfused patient of $1.4 \%$ with anti-E being the most common specificity followed by anti-D, anti-e, anti-c, anti-E, anti-C + D, and anti-K respectively. ${ }^{(15)}$

Our study, taking in account all of the incompatible cross match in contrast to other study show that autoantibodies were the reason of incompatible cross match in about half of these case. About one fourth of these incompatible cases reveled presence of alloantibody. Anti $M$ being the most frequent alloantibody followed by anti-c, anti-D, anti-e, anti-E, and anti$\mathrm{Jk}^{\mathrm{a}}$ and anti S antibody. Only two of these cases to be found to be 
having multiple antibodies (anti-E with $\mathrm{K}$ and anti-C with $\mathrm{E}$ and $\mathrm{K})$.

\section{CONCLUSION:}

The purpose of pre-transfusion compatibility testing is to ensure the transfusion of safe blood components. It is necessary to detect the red cell antibodies to prevent hemolytic transfusion reaction during or after allogeneic transfusion. As the antibody screening is not a routine part of compatibility testing in our part of world, due to economic factor the importance of proper serological cross match cannot be overemphasized. All incompatible cross match case should be further investigation to detect clinically significant antibodies, if any, and to provide the transfusion of antigen negative blood where required. It is further suggested that the patient requiring multiple transfusion should be considered for red cell phenotype match transfusion to avoid the risk of all immunization.

\section{REFERENCES}

[1] Jeremiah ZA, Mordi A. Evaluation of the clinical utility of maternal alloantibody screening as a surrogate to antiglobulin crossmatch procedures in resource limited settings. International Journal of Blood Transfusion and Immunohematology. 2011;1:1-6.

[2] Mukherjee KL. Medical Laboratory Technology Volume 3: Tata McGrawHill Education; 2013.

[3] Quirino MG, Colli CM, Macedo LC, Sell AM, Visentainer JEL. Methods for blood group antigens detection: cost-effectiveness analysis of phenotyping and genotyping. Hematology, transfusion and cell therapy. 2019;41(1):44-9.

[4] Zaman S, Chaurasia R, Chatterjee K, Thapliyal RM. Prevalence and specificity of RBC alloantibodies in Indian patients attending a tertiary care hospital. Advances in hematology. 2014;2014.

[5] Harmening DM. Modern blood banking \& transfusion practices: FA Davis; 2018.

[6] Johnson ST, Brown MR, Slayten JK. Blood group antigens and antibodies. Transfusion Medicine, Apheresis, and Hemostasis: Elsevier; 2018. p. 11342.
[7] Al-Joudi F, Ali AB, Majdan Bin Ramli SA, Ismail M. Prevalence and specificities of red cell alloantibodies among blood recipients in the Malaysian state of Kelantan. Asian Journal of Transfusion Science. 2011;5(1):42.

[8] Isaac I, Osaro E, Adias T, Isezuo S, Imoru M, Udomah F, et al. Prevalence of Clinically Significant Alloantibodies among Transfusion Requiring Patients in a Tertiary Hospital in Sokoto, Nigeria. International Blood Research \& Reviews. 2017:1-9.

[9] Pahuja S, Gupta SK, Pujani M, Jain M. The prevalence of irregular erythrocyte antibodies among antenatal women in Delhi. Blood Transfusion. 2011;9(4):388.

[10] Yang EJ, Shin K-H, Song D, Lee S-M, Kim I-S, Kim H-H, et al. Prevalence of Unexpected Antibodies in Pregnant Korean Women and Neonatal Outcomes. The Korean Journal of Blood Transfusion. 2019;30(1):23-32.

[11] Ismail W, Al-Hassan FM, Shatar AKA, Roslan MNF, Rosdan NH, Zainuddin N, et al. Prevalence of red cell alloantibodies among multi transfused dependent thalassemia patient in the Malaysian state of Penang. Journal of Scientific Research and Development. 2016;3(2):62-6.

[12] Mangwana S, Bedi N, Simon N. Red cell autoantibodies: Selection of blood for transfusion. Global Journal of Transfusion Medicine. 2017;2(2):159.

[13] Walker R. The antiglobulin test. Technical manual. American Association of Blood Banks. 10th ed. Arlington, VA, Karger; 1990.

[14] Britannica E. Available online: https://www. britannica. com/place. Brazil (accessed on 27 March 2018). 2018.

[15] Mangare C, Mbugua A, Maturi P, Rajab J, Blasczyk R, Heuft H-G. Red cell allo-and autoimmunisation in transfused sickle cell and cancer patients in Kenyatta National Hospital, Nairobi, Kenya. African Journal of Laboratory Medicine. 2015;4(1):1-7.

\section{AUTHORS}

First Author - Dr. Jamil Ahmad, Doctor of Medical Laboratory Sciences (DMLS) + Clinical Transfusion course, jamilahmad2424@gmail.com

Second Author (co-Author) - Dr. Hassaan Bin Sohail, DMLS, Third Author - Dr. Lubna Humayun, (Pathologist)

Fourth Author - Dr. Atiya Begum, (Pathologist)

Fifth Author - Dr. Bilal, (DMLS)

Sixth Author - Irfan Ullah, (DMLS) 